\section{Galileo's trial}

SIR - Your recent leading article "Why bother to rehabilitate Galileo?" (Nature 30 October $1980 ; 287,767-768$ ) begins with a pertinent review of Galileo's trial. The last part of the article unfortunately becomes an arbitrary critique of the twentieth century Catholic Church which does not belong in a scientific journal like Nature.

More important though, some errors are present. For instance, it is stated that directed evolution plays a "big part in the Church's view of biology", that the Big Bang is "leaped at" by the Church and that the scientific failure of these two theories would place the Church in an indefensible position. These three statements are invalid.

The official Church never taught "directed evolution". Teilhard de Chardin never was a "doctor of the Church" and the official theology of the Catholic Church is still founded on the works of men such as St Thomas Aquinas, who admitted the possibility that the world apparently acts as moved by the laws of fate and necessity (see also St Augustine).

The Big Bang was once kindly considered (but never affirmed) by Pope Pius XII. And some modern astronomers actually claim that the Big Bang is a proof of God (which is either stupid or blasphemous, and perhaps both). The finiteness or infiniteness of space, time and the number of intelligent beings in the Universe are not fundamental problems and have no bearing on the primary question "Why existence?". Science and God, for the Catholic Church, do leave the individual free to answer such questions for himself, and it seems useful that you should be aware of the affirmation of Pius XII, Paul VI and John-Paul Il that science and faith each have their own field.

The article "Why bother to rehabilitate Galileo?" ends with categorical criticism of the Church's moral (sexual) recommendations. What is the point of this? The Church proposes a way of life (responsible paternity) to people who believe in the Church and in the eternal destiny of men. Ethics is not a consequence of science.

Then you continue to say peremptorily that "The Church's views on birth control are a means of making millions of small-time martyrs, pathetic contemporary analogues of Galileo" - what can be said of abortion, which involves an act similar to that of the men who condemned Galileo?

Henri Reboul

Université des Sciences et

Techniques du Languedoc, Montpellier, France

\section{Don't be vague}

SIR - Mr Ronald Reagan may indeed be conservative but he is surely not so backwardlooking as to choose a British First World War general as his Secretary of State (Nature 18/25 December 1980, p.631).

DAvid PIKE

King 's College Hospital,

London SE5, UK

Secretary of State Alexander Haig was

inexcusably confused with Earl (Douglas)

Haig (1861-1928) - ED. Nature

\section{Evolutionary thought}

SIR-At a time when irrationalism is gaining ground against science in popular culture I feel that I must echo some of Dr Halstead's misgivings about the use of cladistics to explain the process of evolution'. However, his castigation of Engels as the eminence grise behind cladistics is unfounded and is based upon a misunderstanding of how dialectical materialism explains discontinuous development in both nature and society.

Halstead (with Popper) sees Marxism as "working to spark off the revolution", 2 . This is the sort of ultra-leftism espoused by the early German Communist Party and later by Stalin in his "Third Period". Lenin in "Leftwing Communism - an infantile disorder" answered the former and Trotsky the latter in "Revolution Betrayed". In the biological sciences, organic change may be either gradual or discontinuous. Darwin by over-reacting to "leaps" in development, which he saw as the "new creations" of his religious opponents, ended up by formulating a theory of inheritance based on the blending of acquired characters - pangenesis. This ultragradualism was overthrown by genetics which reinstated the view of saltatory leaps, now based on mutations. Dialectical materialism properly understood proposes neither an opening for deism nor mutational leaps. It does propose the transformation of quantitative developments (genetic mutations and changes in ecology) into a qualitative leap in development (not in structure but in selection pressure). A genetic mutation per se is a leap, but not a dialectical leap.

The clearest examples of dialectical change in evolution are in the area of so-called macroevolution, where quantitative genetic changes taking place to fit an organism for one habitat pre-adapt the organism to "leap" into another ecological niche where the selection pressure is qualitatively different. Darwin describes this type of development in the speciation of the Galápagos finches, although not referring to it as a leap. The early diversification of the mammals has been described by Olson ${ }^{3}$ as due to "Co-ordination and integration of such modifications (as) brought some members of a particular radiation to the threshold of a new radiation". Similarly, many workers explain the initiation of major periods of diversification or the invasion of new environments by such a "quantitative to qualitative and back to quantitative"' hypothesis.

Even G. G. Simpson, to whom the mechanistic view of cladism may or may not have been anathema, was by no means averse to the idea of leaps. I quote: "Even within the staid horse family, which seems as a whole to be progressing rather steadily through the Tertiary, close examination shows the rates varying considerably. More broadly, evolution commonly seems to proceed in spurts and pauses in an apparently erratic way"4.

Department of Zoology, Mike Howgate

\section{University College London,}

London $W C l, U K$

1. Halstead L. B. Nature 288, 208 (1980).

2. Halstead L. B. New Scient. 17 July 1980, p.215.

3. Olson E. C. Vertebrate Paleozool, 673 (Wiley-Interscience, 1971).

4. Simpson G. G. The Meaning of Evolution, 103 (Yale University Press, 1976).
Engels on Darwin

SIR - How right Dr Halstead is to remind us of the lengths to which Marxists have gone, and will no doubt continue to go, in their efforts to place their materialist theory of history on a scientific par with Darwin's evolutionary theory. Engels, no less, argued, in his oration at Marx's funeral, that “. . . just as Darwin discovered the law of development of organic nature, so Marx discovered the law of development of human history...,

Incidentally, it is worth recalling that the only Englishman at the graveside to hear this, was Marx's erstwhile young friend Ray Lankester FRS. Lankester was later knighted and served as the Director of the Natural History Departments of the British Museum (1898-1907), and is still remembered for his reclassification of the Talpidae collection. The plot thickens! Birmingham 13, UK

HARRY CRABTREE

\section{Motorbike safety}

SIR - A recent letter to Nature ${ }^{1}$ concerns the observation that an object appears to maintain constant size as its distance from the observer changes. It is simply "seen" as a full-sized object at varying distance. This size constancy fails quite suddenly when the object subtends an angle at the observer of less than half a degree; it is then seen as a small object, presumably of less immediate importance.

This phenomenon could be a contributory factor in a fairly common type of road traffic accident, that caused when a driver pulls out unexpectedly in front of motorcyclist who is then unable to stop.

An approaching motorcyclist presents an irregular silhouette subtending an average angle of less than half a degree at any distance greater than about 200 feet. If size constancy fails below half a degree, the motorcyclist would only be seen as small, and would therefore be less likely to register subconsciously as a real full-sized danger, until within about 200 feet.

The shortest possible stopping distances for a moving vehicle under good conditions are reported in the highway code as follows Vehicle speed (m.p.h.) $\quad 30 \quad 40 \quad 50 \quad 60 \quad 70$

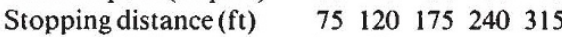

Interpolation suggests that when a motorcycle is approaching at over 54 m.p.h., so that its stopping distance is greater than the critical 200 feet, an accident might be inevitable, particularly if either driver was not concentrating on "seeing" the other vehicle at the crucial time. Many similar calculations are possible. A convex rear view mirror reduces the image size and so can make it possible for larger vehicles to approach within their stopping distances before they, too, subtend the critical angle of half a degree.

Much work has been done on the effect of factors such as brightness, contrast, colour, shape, size (and styling features disguising shape and size) on the visibility of an object. The results of this work might valuably be applied to problems of the type outlined above G. K. MCGINTY

Redhill, Surrey, UK

. Ross J., Jenkins B. \& Johnstone J. R. Nature 283 , $473-474$ (1980). 